\title{
Estrategias productivas familiares, percepciones y deforestación en un contexto de transición forestal: el caso de Tena en la Amazonía ecuatoriana
}

\author{
Susana Anda Basabe \\ FLACSO Ecuador \\ gsandab@gmail.com
}

\section{Sara Gómez de la Torre}

FLACSO Ecuador

sara.gomezdelatorre@gmail.com

\section{Eduardo Bedoya Garland}

FLACSO Ecuador

ebedoyagarland20@gmail.com

\section{RESUMEN}

Este artículo explica la forma como las estrategias productivas familiares de los colonos agricultores y las percepciones que los agricultores tienen sobre el bosque influyen en el ritmo de deforestación. Este tipo de enfoque, basado en el análisis de procesos endógenos, procura contextualizar y entender cómo los agricultores funcionan dentro de un contexto de «transición forestal», resultado de significativos cambios económicos, expansión del mercado y desarrollo de la infraestructura vial. Nuestro argumento central es que las indicadas estrategias de los agricultores en el cantón de Tena, en relación con el ritmo de deforestación en sus fincas, se construyen como resultado de la combinación de un conjunto de procesos económicos de sobrevivencia a corto y mediano plazo y desde los cuales se elaboran percepciones mentales o culturales sobre el bosque. Tales procesos endógenos no son únicamente respuestas a contextos externos sino 
que también se derivan de ciclos demográficos y dinámicas de acumulación que ocurren dentro de las familias de los productores.

Palabras clave: Amazonía, colonos, transición forestal, deforestación, percepción cultural

\title{
Family productive strategies, perceptions and deforestation in a con- text of forest transition: the case of Tena in the Ecuadorian Amazon
}

\author{
SUMMARY
}

This article explains how the family productive strategies of farmer settlers and their perceptions of the forest influence the rate of deforestation. This particular approach, based on the analysis of endogenous processes, seeks to contextualize and understand how farmers operate within a context of "forest transition», as a result of significant economic changes, market expansion and road infrastructure development. Our central argument is that the farmers' strategies in Tena, in relation to the rate of deforestation on their farms, are a result of the combination of a set of economic processes of survival in the short and medium term and of their mental or cultural perceptions of the forest. Such endogenous processes are not only responses to external contexts but are also derived from demographic cycles and accumulation dynamics that occur within the families of producers.

Key words: Amazonia, Colonists, forest transition, deforestation, cultural perceptions. 


\section{INTRODUCCIÓN, OBJETIVOS Y METODOLOGÍA}

En un artículo anterior demostramos la importancia de la agricultura migratoria en la Amazonía ecuatoriana, más conocida como sistema de tala, rozo, quema, siembra y rotación de suelos, y su influencia en la deforestación tropical (Gómez de la Torre, Anda y Bedoya, 2017). Dicho trabajo se sustenta en los resultados de un estudio realizado en Tena, cantón de la provincia de Napo, en la zona norte de la Amazonía a 510 msnm, durante el año 2014 (ver mapa) ${ }^{1}$. En ambos textos centramos nuestro análisis en demostrar la importancia de variables tales como el tamaño del predio, la antigüedad de la finca, la orientación económica de los agricultores, su racionalidad individualista y su correspondiente impacto en la destrucción de bosques.

En esta ocasión, incluimos otros factores igualmente significativos tales como, en primer lugar, las estrategias productivas familiares de los colonos agricultores; en segundo lugar, la mayor o menor diversificación ocupacional y productiva, y finalmente, en tercer lugar, las percepciones que los agricultores tienen sobre el bosque. Estas variables se analizan dentro de un tipo de enfoque basado en el análisis de procesos endógenos que procura contextualizar y entender cómo los agricultores funcionan dentro de un contexto de «transición forestal», resultado de significativos cambios económicos, expansión del mercado y desarrollo de la infraestructura vial (Sierra, 2013; Rudel, 2002) y de un «cierre de frontera»o escasez inicial de tierras de frontera (Barbieri, 2005), consecuencia esto último de las crecientes titulaciones de territorios indígenas, la delimitación de tierras

La investigación fue realizada con el financiamiento de SENESCYT (programa Prometeo) y el auspicio de la Facultad Latinoamericana de Ciencias Sociales (FLACSO-Quito), durante el año 2014. En FLACSO tuvimos el valioso apoyo de Teodoro Bustamente, Anita Krainer, Nicolás Cuvi, Ivette Vallejo y Carolina Garzón. En Anaconda-Tena, la generosa acogida, apoyo y compañía de Francisco y Silvia Rodríguez. 
consideradas como zonas protegidas o parques nacionales y el ordenamiento territorial y forestal. Si en las décadas de 1960, 1970 y 1980 existía una frontera abierta con una amplia disponibilidad de tierras, en las de 1990 y 2000 la frontera empieza a cerrarse y las tierras disponibles se hacen cada vez más escasas debido a las medidas mencionadas, a las que se suma el crecimiento poblacional. Como resultado, se ha producido una fragmentación de las fincas o unidades agropecuarias, producto de la herencia de padres a hijos de segunda generación o de la venta de tierras a nuevos migrantes o a agricultores jóvenes sin tierra. Ello ha restringido - tal como remarca Barbieri- la ampliación de la frontera demográfica y agrícola hacia nuevas regiones como efecto de la disminución en la oferta de tierras. La deforestación sigue siendo un fenómeno muy visible, pero ocurre sobre todo dentro del mismo predio o finca agrícola. Cada vez se deforestan más los bosques secundarios y menos los bosques vírgenes. La agricultura migratoria practicada por invasores permanentes de tierras alejadas, todavía es una realidad, pero está más restringida que en décadas anteriores dado el mencionado cierre de la frontera.

Mapa de Ecuador. Localización del cantón de Tena en la Provincia de Napo. 2014.

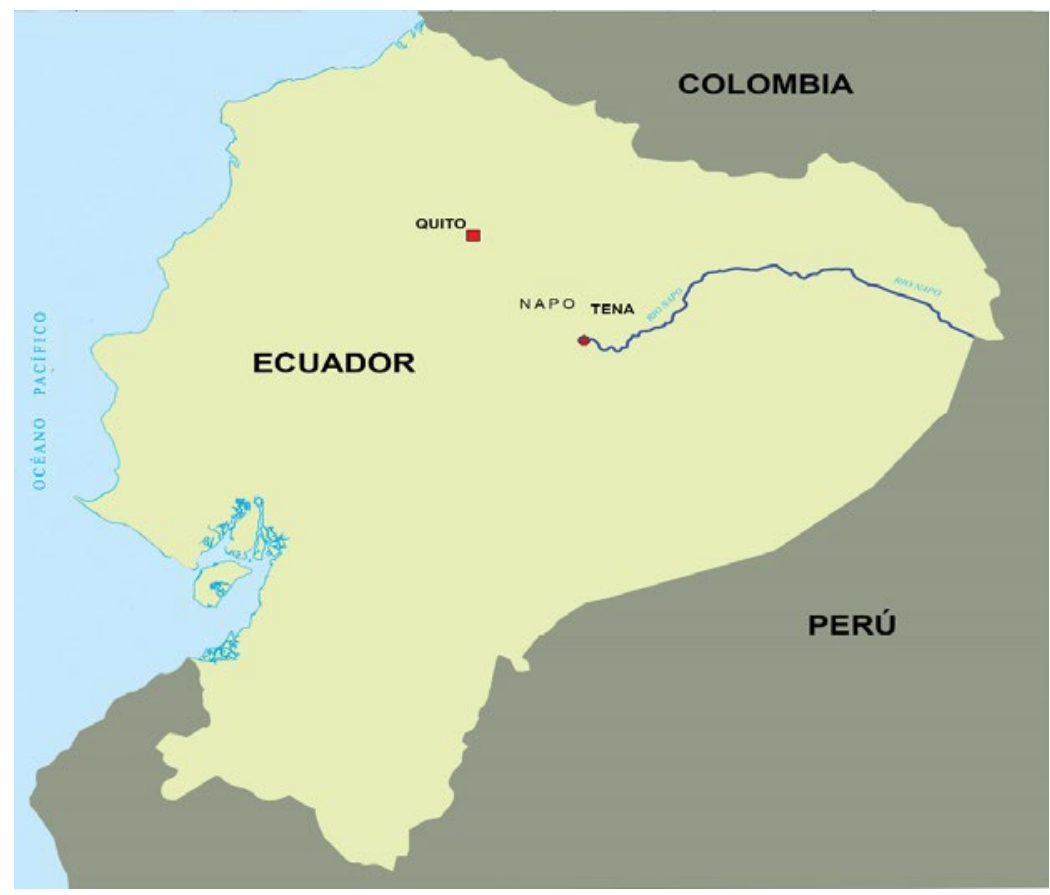

Elaborado por Manuel Kingman para este artículo. 
Para fines de nuestra investigación, utilizamos la metodología propuesta desde la ecología política por Bryant y Bailey (1997) y Bryant (1998), que busca la articulación de distintas escalas de análisis, tales como la dinámica productiva familiar y los procesos económicos, políticos e institucionales que suceden en un nivel macro, todo ello a través de una pluralidad de disciplinas de las ciencias sociales, e incluso de las humanidades. Siguiendo la misma lógica, en la sección final del artículo recurrimos al análisis de lo que Pálsson (1996, p. 65) denomina «la economía política de la dicotomía moderna entre naturaleza y sociedad», con el objetivo de analizar cómo, en un contexto de cierre de frontera o escasez de tierras, los colonos y colonas individuales en Tena oscilan entre una reciprocidad negativa (comunalismo) y una más equilibrada (paternalismo), en sus percepciones sobre el uso de los recursos naturales y el bosque primario y secundario.

En ese sentido, la hipótesis central del texto es que las indicadas estrategias de los agricultores en el cantón de Tena, con relación al ritmo de deforestación en sus fincas, son resultado de la combinación de un conjunto de procesos económicos de sobrevivencia a corto y mediano plazo y desde los cuales se elaboran percepciones mentales o culturales que ellos manejan sobre el bosque. No obstante, tales procesos endógenos no son únicamente respuestas a contextos externos, tales como la transición forestal y el cierre de fronteras, sino que también se derivan de ciclos demográficos y dinámicas de acumulación interna que ocurren dentro de las familias de los productores. Fundamentamos nuestro análisis en un total de ochenta encuestas y veinte entrevistas a profundidad realizadas durante el trabajo de campo. El presente trabajo tiene un rasgo metodológico bastante etnográfico $\mathrm{y}$, sin embargo, también recurre a la información recogida en las encuestas. Uno y otra se complementan.

Cabe indicar que autores tales como Bilsborrow (1997, 1994), Pichón y Bilsborrow (1999) Pichón (1997) y más recientemente Flora Lu et al. (2010), Barbieri et al. (2006) y Bilsborrow et al. (2004), han abordado la temática de la deforestación incorporando el análisis más estrictamente demográfico (tamaño de la familia, fecundidad y mortalidad) articulado a los cambios socioambientales de la Amazonía ecuatoriana. Otras investigaciones anteriores han analizado la racionalidad productiva de las unidades familiares de los colonos en una zona de frontera demográfica y agrícola de amplia disponibilidad de tierras y escasez de mano de obra en la Amazonía ecuatoriana, brasileña, peruana y en regiones tropicales de Centroamérica.

Por ejemplo, Pichón (1996) abordó el caso de los colonos en la Amazonía ecuatoriana y estudió la deforestación a partir del análisis de la dinámica de 
asignación de recursos en un contexto de frontera, donde existe una integración al mercado muy desfavorable, un débil apoyo institucional crediticio y técnico del Estado, y en muchos casos, una inseguridad jurídica sobre la tenencia de los predios (Pichón, 1996, p. 358). A los agricultores colonos, según Pichón, les interesa más la seguridad económica a largo plazo que incrementar la productividad de uno o dos productos, lo cual induce a la ocupación de más tierras y destrucción de bosques (Ibíd.). Seguidamente, los estudios de Perz (2001), Perz et al. (2002), Deadman et al. (2004), Walker et al. (1996) en la Amazonía de Brasil; Bedoya (1995) y Aramburú y Bedoya (1986) en el Perú, y Godoy et al. (1997) en Honduras han descrito el proceso de toma de decisiones de los agricultores y su impacto en el uso del suelo y la deforestación, analizando el ciclo de vida de la familia. En este caso, la disponibilidad de mano de obra familiar constituye un aspecto fundamental — sobre todo en las fases iniciales de la colonización - e igualmente en el proceso de crecimiento del denominado «realce» (término ecuatoriano de purma en el Perú), «monte grande» o bosque secundario.

\section{LA TRANSICIÓN FORESTAL EN ECUADOR}

Tal como resumen e indican Angelsen y Rudel (2013, p. 93), el concepto de transición forestal fue originalmente formulado por Mather (1992) y posteriormente refinado por el mismo autor (Mather y Needle, 1998), y más recientemente por otros autores y geógrafos tales como Pfaff y Walker (2010). La indicada teoría predice en el transcurso del tiempo un patrón más o menos sistemático de transformación en la cobertura forestal en un país o región. En un principio, un país tiene un porcentaje muy alto de tierra bajo cubierta forestal, fase que Angelsen y Rudel (2013, p. 91) denominan como forest cover o bosques de cobertura densa, dentro del ciclo de la transición forestal. No obstante, en países en desarrollo, como aquellos de la cuenca andina amazónica, la necesidad de expandir la frontera agrícola y demográfica impulsó la colonización hacia tierras bajas tropicales y, por lo mismo, la destrucción de bosques, causando que dicha cubierta forestal se redujera. Esta segunda fase se llama frontier forest o bosques de frontera. Posteriormente, en su momento, resultado del mayor desarrollo económico urbano en el sector servicios e incluso industrial y del correspondiente aumento de salarios urbanos, la deforestación disminuye, «seguida por un punto de inflexión (es decir, de la deforestación neta a la reforestación neta) y un lento proceso de recuperación forestal» (Angelsen y Rudel, 2013, p. 93). Ello equivale a la tercera fase de la transición forestal y se denomina como frontier agricultural mosaics $\mathrm{o}$ 
frontera agrícola formada por mosaicos de bosques y espacios agrícolas (p. 93). Cabe indicar que la transición forestal se asemeja mucho a la curva ambiental de Kuznetz. Las variables más importantes que determinan la transición forestal son el desarrollo económico y la migración rural urbana, en el período final.

No obstante, la teoría de la transición forestal no ha logrado constituirse en un marco teórico homogéneo y ha sido susceptible de una serie de críticas. Entre otros aspectos se señala que: (i) por ahora es mejor solo considerarla como una generalización histórica; (ii) en el contexto de la globalización, la demanda de algunos productos, como el aceite de palma, ha frenado la transición forestal y, por ende, la reforestación; (iii) carece de suficiente evidencia empírica; (iv) no diferencia entre bosques secundarios y primarios en la fase de reforestación, dado que ambos tipos de bosques tienen características y funciones ambientales diferentes; (v) es aplicable a ciertos contextos y otros no; (vi) deben tenerse en cuenta las fuerzas sociales que empujan o desvían la transición forestal, y (vii) debe distinguirse entre la dinámica a corto y largo plazo de la transición forestal (Perz y Skole, 2003, p. 290).

A pesar de todas las críticas mencionadas, Rodrigo Sierra (2013) presenta muy recientemente pruebas contundentes sobre la relación entre crecimiento económico y disminución de las tasas de destrucción de bosques en el Ecuador. Para dicho autor, este proceso - bastante complejo y contradictorio - solo puede entenderse a través del análisis de las grandes transformaciones estructurales que vive Ecuador desde la década de 1990. Según Sierra (2013), entre 1990 y 2008 se perdieron cerca de 19000 kilómetros de bosque natural en todo el país. Sin embargo, la mayor parte, cerca del 70\%, fue deforestada en la década de 1990. Entre los años 2000 y 2008 la deforestación anual promedio en Ecuador fue de 753,9 kilómetros cuadrados frente a los 1291,5, del período 1990-1999. Es decir, en los primeros ocho años de este siglo se produjo una caída de $42 \%$ respecto de la década de 1990. Más aún, el área deforestada neta cayó en casi todas las regiones del país. En las provincias, únicamente Morona Santiago y Bolívar tuvieron aumentos netos en la deforestación anual en ambos períodos (Sierra, 2013).

Según Sierra (pp. 20-24), si en un principio la expansión de la frontera agropecuaria se dio bajo una modalidad de extensificación, en las últimas décadas viene ocurriendo bajo la forma de intensificación de uso del suelo, a través del incremento de la productividad agropecuaria. Para dicho autor, el aumento de «la intensificación de los sistemas productivos rurales» vino acompañado de «mejoras en la accesibilidad en casi todos los sectores rurales del país», de la caída 
de las tasas de natalidad de la población ecuatoriana y de la «consolidación de los derechos de propiedad de las áreas forestales remanentes»; en otras palabras, en un cierre de la frontera colonizadora.

Sin embargo, uno de los factores que más impulsaron el proceso de intensificación agrícola fue el incremento de los ingresos urbanos y rurales no agropecuarios. Según el mencionado autor (p. 24), en la primera mitad de la década de 1990 el PIB creció un promedio de 3\% anual, con caídas importantes en las tasas de inflación. En el año 2000, el ingreso promedio rural equivalía al $65 \%$ del ingreso nacional promedio y al $56 \%$ del ingreso promedio urbano. Ello constituyó un fuerte incentivo para que se produjesen importantes procesos migratorios rural-urbanos o a zonas con mejor acceso a los nuevos puestos de trabajo, cercanas a las carreteras, aunque ello también generó una mayor demanda de nuevos productos agropecuarios. Seguidamente, entre 1990 y 2001, el empleo urbano aumentó 2,5 veces más que el rural. Al interior del empleo rural, solo el $53 \%$ de los nuevos puestos de trabajo se dieron dentro del sector agropecuario. Mientras que la hotelería, recreación y comercio si tuvieron un aumento relativamente importante. Todo ello causó, según Sierra (p. 24), una disminución en las tasas de deforestación, dado que redujo la demanda de empleo en los sectores estrictamente rurales.

Todo este conjunto de datos y tendencias, bastante complejas y un tanto contradictorias, conducen a Sierra a concluir que la deforestación en Ecuador debe ser analizada en dos escalas temporales. A escala global, la tendencia es que la deforestación se reduzca como consecuencia de las transformaciones estructurales, que empujan al país hacia una dinámica de intensificación de las áreas agropecuarias. A corto plazo, no obstante, la deforestación aparece directamente vinculada con los ciclos económicos nacionales (p. 24).

Bajo esta perspectiva, la deforestación coincide inversamente con el crecimiento de la economía, e incluso con la reducción de la desigualdad en la distribución del ingreso nacional. La deforestación se intensifica en las áreas de mejor acceso, pero baja en las áreas más alejadas (p. 39). En las zonas alejadas, debido a que los costos de producción son muy altos y la disponibilidad de mano de obra es menor para las labores de desbosque, los bosques se mantendrán intactos o resurgirán si es que hubo deforestación. En las zonas cercanas, las actividades de transformación del bosque se incrementarán. Según Sierra, en la suma global neta la deforestación tiende a disminuir. Es decir, Ecuador estará ingresando a una etapa de transición forestal, que corresponde a un proceso de urbanización acelerada acompañado por una transición demográfica avanzada (p. 40). 
Un argumento similar respecto de la transición forestal elabora Rudel (2002, pp. 98-99) para la región de Macas, en la provincia ecuatoriana de Morona Santiago. Sin embargo, señala que dicha transición es diferente de la sucedida en Europa en los siglos XIX y XX. En el caso ecuatoriano, no ha significado necesariamente abandono de tierras, sobre todo en las más cercanas a las carreteras, sino una reconversión de pastizales a tierras dedicadas a cultivos intensivos orientados al mercado nacional y extranjero. Ello ha sucedido, por ejemplo, entre la población Shuar. Figura distinta sucede con la población mestiza, que además de abandonar las zonas alejadas, ha dejado la actividad agrícola en su conjunto (pp. 98-99). Los datos que a continuación presentamos tienden, de una forma u otra, a demostrar y evaluar de manera crítica cómo los agricultores de Tena se desenvuelven justamente en un contexto de transición forestal, y para ello, recurrimos a los resultados obtenidos en encuestas y entrevistas utilizando el método etnográfico.

En ese sentido, cabe indicar que las visitas y entrevistas de campo, como también las fotos aéreas de Tena, nos han demostrado la existencia de un paisaje rural que encaja más con la fase final de la transición forestal. Concretamente, se asemeja a un mosaico de sistemas agrícolas de producción de cultivos anuales o ciclo corto, conjuntamente con plantaciones de cacao, café e intercalados con sectores cubiertos por bosques secundarios y también primarios. En menor medida se observan lotes ganaderos, en contraste por ejemplo a Macas. En ese sentido es importante recalcar que, en los predios encuestados por el estudio en Tena, el bosque virgen ocupa un promedio de $36 \%$ en el conjunto del área cubierta. Este porcentaje es ligeramente mayor a lo encontrado por Perz y Skole (2003, p. 288) respecto de lo que se comprueba en regiones de colonización antigua del Brasil de la denominada Amazonía legal y que oscilan alrededor del 23\% de los predios. Sin embargo, en los predios más pequeños de 0,5 y menos hectáreas el bosque virgen cubre un $7 \%$ y en los de 5,1 a 10 ha, un $26 \%$. No obstante, en los predios o fincas mayores de 10,1 y 30 ha, el porcentaje promedio alcanza el $70 \%$ y en las de más de 30 ha, un 39\%. Esto último por la existencia de fincas ganaderas. En otras palabras, un aproximado de cuatro décadas de agricultura rozo y rotación de suelos o de rozo y quema en otros casos, no han destruido la totalidad del bosque primario en los predios donde se aplicaron encuestas y entrevistas ${ }^{2}$.

2 Cabe indicar que la quema en la zona no es una práctica universal puesto que los meses o estaciones de menor cantidad de lluvias no son tan marcadas como en otras regiones de la Amazonía. Algunos agricultores queman los troncos cortados y otros no lo hacen. Los que no lo hacen dejan que se pudran los troncos como medio de fertilización natural (Pichón, 1997). 


\section{ESTRATEGIAS PRODUCTIVAS DE LOS COLONOS EN EL TENA EN LA DÉCADA DE 1970 Y SIGUIENTES EN UN CONTEXTO DE FRONTERA ABIERTA}

Los habitantes colonos más antiguos que ocuparon desde las décadas de 1960 y 1970 la región amazónica de la provincia de Napo fueron individuos o familias jóvenes que provinieron de otras regiones del Ecuador, específicamente de la sierra y costa ecuatoriana. Eran campesinos agricultores que se vieron presionados a buscar tierras debido a las sequías o a la falta de terrenos en el lugar de procedencia, de tal forma que la migración en dirección de las tierras tropicales, como bien afirma Macdonald (1997, p. 233) suponía «la respuesta de los problemas de la tenencia de tierras en la Costa y la Sierra». La selva representaba un espacio vacío de tierras de abundantes para aquellos que no las tenían. Diversas campañas propagandísticas difundidas por instituciones públicas a través de las radios promovieron la colonización del oriente ecuatoriano, presentándola como una nueva oportunidad para mejorar la calidad de vida de los campesinos a través del acceso y posesión de grandes extensiones de tierras de libre disponibilidad, y prometiéndoles convertirse en prósperos finqueros o ganaderos (Uquillas, 1986, p. 366; Uquillas, 1984). De ese modo, una cantidad significativa de colonos de la parroquia de Ahuano, cantón de Tena, migraron desde las provincias de Bolívar, Loja, El Oro y Los Ríos. Alentados y entusiasmados por tales mensajes, numerosos jefes de familia, organizados en grupos, salieron en búsqueda de tierras para trabajar en la Amazonía. Arribaron primero al Tena con la finalidad de encontrar apoyo del Instituto Ecuatoriano de Reforma Agraria y Colonización (IERAC), institución creada en la década de 1960 (Uquillas, 1986, p. 368). A continuación, con la ayuda de las empresas constructoras que tenían canoas para transportar materiales, maquinaria e incluso acceso a mano de obra, se les facilitó el traslado hacia nuevas áreas de la selva amazónica. Algunos agricultores pioneros utilizaron los servicios de otros colonos que llegaron poco antes y que brindaban conocimientos sobre tierras que podrían ser ocupadas, además de la venta de comida.

Los nuevos habitantes fueron en busca de tierras abundantes, fértiles y sin dueño. Luego de inscritos en el IERAC, se apropiaron de tierras «baldías» (preferentemente planas) que medían alrededor de 50 hectáreas, donde grandes proporciones de bosque primario serían deforestadas para el cultivo individual. En un principio los colonos llevaron el modelo agrícola diversificado de sus regiones de procedencia, donde la producción consistía en el cultivo de café, cacao, yuca, maíz, plátano y arroz, hacia las «nuevas» tierras amazónicas. No obstante, 
encontraron que, en la selva, después de dos cosechas se acababan las matas de plátano a diferencia de la región litoral, donde el plátano dura «toda la vida». Los rendimientos decrecientes aparecieron más rápido que lo que se imaginaron.

Tal como sucedió en otras regiones de colonización (Uquillas, 1986, pp. 366-367), las primeras casas se construyeron cerca de las vías de comunicación y alrededor de ellas se talaron pequeñas parcelas donde se sembró «lo suficiente» para abastecer el autoconsumo de las familias; es decir, en no más de media hectárea se cultivaron productos como plátano y yuca. Luego extendieron la tala hacia nuevas parcelas en su terreno y empezaron a sembrar arroz y maíz que servirían para el consumo humano y para la crianza de aves. Cuando se vieron con mayor estabilidad, sembraron café y cacao, ampliando el desbosque para extender el cultivo de estos productos en parcelas cuyas extensiones medían más de cinco hectáreas. Aunque en un principio el café no produjo mayores cosechas y algunos colonos se fueron de sus tierras desilusionados, aquellos que se mantuvieron en los terrenos adquiridos en las zonas más alejadas de las vías de comunicación (como en el caso de los habitantes de la comunidad Dorado Huambuno) insistieron en este cultivo, consiguiendo mejorar la producción después de diez años de trabajo. Dada la abundancia de pescados en el río y animales en el bosque, algunos colonos aprendieron a pescar y cazar, imitando prácticas de los napokichwas y huaorani, nacionalidades amazónicas que habitaban y aún residen en el Tena (Trujillo, 1986, pp. 428-432). Otros, luego de un período razonable de acumulación y ahorro, instauraron comedores y tiendas cerca de los ríos (que se constituían como las principales vías de comunicación) donde vendían mercancías que no se producían localmente.

A mediados de la década de 1970, durante el gobierno de Guillermo Rodríguez Lara (1972-1976), período en el que empezó la explotación petrolera, el Estado otorgó préstamos para que los campesinos trabajaran sus tierras. Motivados por las políticas crediticias, muchos campesinos empezaron a deforestar para sembrar potreros destinados a la actividad ganadera, y otros mantuvieron sus actividades orientadas en la agricultura. Sin embargo, los colonos que priorizaron la actividad agrícola no obtuvieron los créditos, dado que debían tener potreros para el ganado para acceder a ellos, por lo que se mantuvieron cultivando cacao, café, maíz, plátano, arroz, y en algunos casos, caña de azúcar (Grijalva et al., 2009, pp. 94-96). Las estrategias productivas de sobrevivencia se orientaban a producir tanto para para el autoconsumo como para la venta, lo cual les permitiría cubrir los gastos principalmente de salud para la familia y educación de los hijos. Por su parte, en la época del triunvirato (1976-1979), la introducción de misiones religiosas en la 
provincia de Napo fue primordial, en cuanto se promovió la implantación de escuelas y centros poblados para los colonos. Durante el gobierno de Rodrigo Borja (19881992), los colonos asentados consiguieron una gabarra que les permitiría cruzar el río Napo. En esos años, la instalación parcial de la energía eléctrica, infraestructura de agua potable y la construcción de la carretera Puerto Napo - Zancudo - Colonia Bolívar - Puerto Punta de Ahuano - Ahuano facilitaron las actividades petroleras, comerciales y turísticas (ORDEPLAN, 2012, pp. 9-10). Antes de la construcción de la carretera (1988), muchos agricultores ubicados cerca de la ribera cruzaban el río para vender sus productos. Esta actividad implicaba grandes esfuerzos y riesgos, dado que salían en canoas hacia Misahuallí en un río bastante caudaloso.

La ubicación entre dos y tres kilómetros de distancia de las vías principales implicaba demasiado trabajo para trasladar los productos hacia la carretera, por lo que resultaba más conveniente el trabajo agrícola cerca de las vías de acceso. Con la construcción de la mencionada vía principal, algunos colonos se trasladaron cerca de esta vía de comunicación comprando terrenos a otros colonos, lo cual produjo la tumba del bosque de las nuevas tierras adquiridas para sembrar productos agrícolas. Para la década de 1990, los colonos que habían adoptado la ganadería como actividad prioritaria decidieron remontar los potreros para enfocar sus actividades en la producción agrícola de cultivos de ciclo corto o en frutales destinados a la venta, principalmente de yuca, plátano, naranjilla y maíz. Luego de un período de orientación ganadera, Tena pasó a ser una zona fundamentalmente agrícola. Actualmente, los productos agrícolas prioritarios en las economías familiares colonas siguen siendo los cultivos de ciclo corto, como el maíz y la yuca.

A principios del presente siglo, en el año 2000 se extiende la cobertura de energía eléctrica para las comunidades más alejadas de la cabecera parroquial Ahuano, entre las que se incluyen Campana Cocha, Dorado Huambuno y Nuevo Paraíso, y un año después empieza la construcción de la vía Ahuano - Balsachicta - Campana Cocha - Dorado Huambuno - Patas Yaku. En 2004, culmina la construcción de la carretera Campana Cocha - Huambuno, y en el año 2006 ingresa la compañía Colombia para la explotación de oro en el río Napo (ORDEPLAN, 2012, pp. 9-10). Tena ingresa a un proceso de modernización y urbanización.

En la actualidad, un número de colonos fundadores se encuentran establecidos en los centros poblados de las parroquias locales, donde poseen solares pequeños, no aptos para el cultivo, dado que ya no realizan actividades agrícolas sino que tienen locales comerciales o tiendas. La decisión de este cambio reside en la búsqueda de una opción de vida que permita mayores ganancias con menor trabajo, contrario al esfuerzo que implica la tala de bosque y el trabajo agrícola. 
El mismo patrón ocupacional descrito se ve reflejado entre los habitantes más jóvenes, quienes estudian, van a la ciudad y buscan empleo, por lo que cada vez son menos los habitantes que siguen trabajando en la agricultura. Los jóvenes perciben como más atractivos, más seguros, mejor remunerados, y sobre todo que implican un menor esfuerzo, a los trabajos en la ciudad, y viceversa el trabajo en el campo. Los que se mantienen en el oficio agrícola principalmente son las personas entre cuarenta a cincuenta años que permanecen en esta labor para cubrir los gastos de los estudios de sus hijos y la alimentación de sus núcleos familiares.

En su conjunto, debido a los mencionados procesos migratorios, el cantón Tena experimentó un notable crecimiento poblacional entre la década de 1980 (24 000 habitantes en 1982) e inicios del milenio (46 000 habitantes en 2001) (VI Censo de Población y de Vivienda del 2001). Finalmente, según el censo de 2010, la población se incrementó a casi 61000 personas (VII Censo de Población y VI Vivienda de 2010). Es decir, en los últimos diez años la población del cantón de Tena aumentó en un $24 \%$. Tal incremento fue más significativo en la ciudad del mismo nombre, la cual recibió un flujo significativo de hijos de colonos o colonos de segunda generación. Ello se refleja muy claramente en el peso porcentual cada vez mayor de la población urbana en el cantón de Tena. Entre los años 1982 y 2010, el porcentaje de la población urbana se ha incrementado paulatinamente: en 1982 era el 38,65\% de la población del cantón; en 1990 el 41,9\%; en 2001 el 49,92\% y en 2010, 55,74\% (VII Censo de Población y VI Vivienda de 2010).

\section{CICLO DE VIDA DE LA FAMILIA AGRICULTORA Y DEFORESTACIÓN EN 2014 EN UN CONTEXTO DE FRONTERA CERRADA}

El peso específico del tamaño y la edad de la familia históricamente han influido en las estrategias productivas y laborales de las familias típicamente agricultoras, y en especial campesinas. Las razones de dicha importancia han variado conforme las circunstancias y el contexto local y global, en particular producto de los vaivenes del mercado y el costo de oportunidad de los trabajadores familiares. No obstante, la historia agrícola y el cambio de uso del suelo en las familias de los colonos parece haber seguido un patrón muy similar al de otros países amazónicos, tales como el Perú (Aramburú y Bedoya, 1986, p. 151; Perz, 2001; Perz et al., 2002) y Brasil (Deadman et al., 2004, pp. 695-697). En ambos casos, las estrategias agrícolas dependen inicialmente de la disponibilidad de mano de obra familiar. En las fases iniciales, las familias se componen de hijos pequeños, dado que los que migran son hombres jóvenes a quienes sus parejas siguen luego de uno 
o dos años o se casan con mujeres nacidas en el lugar. En esta fase, la tendencia es sembrar cultivos transitorios o también denominados como cultivos en limpio, tanto para el autoconsumo familiar como para la venta. Los productores colonos siembran entre media y una hectárea de cultivos anuales, tales como maíz y yuca (gráfico 1). Los agricultores venden parte de su producción no con el objetivo de acumular capital sino de obtener dinero y así adquirir productos que ellos mismos no pueden producir en sus parcelas (Pichón, 1996, pp. 352-353). Dichos colonos o hijos de colonos jóvenes trabajan sobre la base de que la maximización del valor de su producción agrícola se logra autoconsumiendo la mayor porción de las cosechas. Es lo que Chevalier (1982) denominó como «mercancías de subsistencia» para el caso de los agricultores colonos en la selva alta peruana.

\section{Gráfico 1. Patrón de uso del suelo según ciclo de vida de la familia agricultora en Tena (2014)}

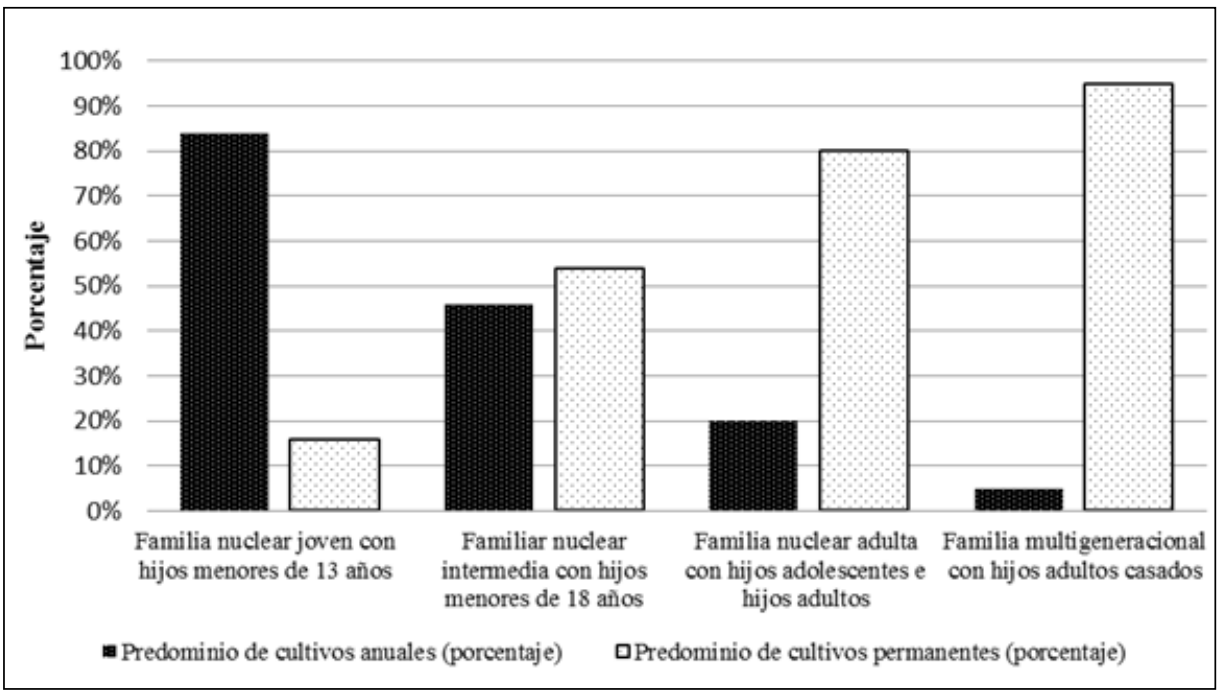

Fuente: Bedoya, Gómez de la Torre y Anda, 2015.

En su conjunto, la estrategia de los colonos o hijos de colonos, en las fases iniciales, es maximizar la seguridad alimentaria y minimizar el esfuerzo de trabajo invertido en las labores del predio agropecuario ${ }^{3}$. Es por ello que en las familias

3 El corte por edad lo hemos realizado por la capacidad o valor productivo que tiene cada hijo o hija en edad de trabajo, el cual naturalmente se incrementa conforme aumenta la edad de los hombres y mujeres adolescentes. El primer grupo o corte se realiza entre las familias con 
nucleares con hijos pequeños la tasa de desbosque suele ser baja (cuadro 1). Los padres no tienen apoyo familiar y tampoco capital para contratar trabajadores. La mano de obra es escasa, tanto en términos absolutos como relativos. En ese contexto, los padres optan por una agricultura de rozo y rotación de suelos muy extensiva que implica deforestación, pero como al principio se orienta al autoconsumo familiar, la extensión deforestada y la tasa de desbosque no es muy alta. Igualmente, para obtener ingresos monetarios diversifican sus ocupaciones trabajando en otro tipo de actividades remuneradas, lo cual reduce la presión sobre el bosque.

\section{Cuadro 1. Tasa de deforestación según tipo de familia entre los agricultores del Tena (2014)}

\begin{tabular}{ll}
\hline Tipo de familia & Tasa anual de deforestación \\
\hline $\begin{array}{l}\text { Familia joven con hijos pequeños menores de } 13 \text { años } \\
\text { (22 casos) }\end{array}$ & 0,69 hectáreas al año \\
$\begin{array}{l}\text { Familia con hijos pequeños y adolescentes de } 13 \text { a } \\
\text { menos de } 18 \text { años ( } 20 \text { casos). }\end{array}$ & 0,37 hectáreas al año \\
$\begin{array}{l}\text { Familia adulta con hijos adolescentes y mayores de } 18 \\
\text { años (28 casos) }\end{array}$ & 1,09 hectáreas al año \\
$\begin{array}{l}\text { Familia adulta con hijos mayores de } 18 \text { años (10 casos) } \\
\text { Fan }\end{array}$ & 1,92 hectáreas al año \\
\hline
\end{tabular}

Fuente: Bedoya, Gómez de la Torre y Anda, 2015.

Sin embargo, dicha estrategia se modifica, y conforme transcurren los años, buscan orientarse hacia otros productos más comerciales en extensiones más grandes y que obviamente demandan mayor esfuerzo. Es así como, al tercer o cuarto año, siembran plantones de cacao o café, cuyo período de maduración suele durar unos años (gráfico 1). En esta segunda fase, paulatinamente las familias incorporan hijos adolescentes al cuidado de las plantaciones, cuyas dimensiones superan las dos hectáreas en promedio. En ese sentido, cuanto más hijos adolescentes o hijos adultos jóvenes que trabajan y consumen dentro del núcleo familiar, mayores son tanto el predominio de las plantaciones de café y cacao

mayoría de hijos menores e aquellas con predominio de hijos adolescentes mayores de trece años. Luego, el tercer grupo está conformado por familias con predominio de hijos adolescentes y adultos. El cuarto grupo se constituye por familias extensas multigeneracionales con hijos e hijas casadas. 
como la tasa de desbosque. En este caso se trata de familias económicamente más consolidadas y también más centradas en las labores agrícolas. Es decir, existe un claro vínculo entre el ciclo de vida de una familia agricultora en el Tena y el impacto en el manejo de los recursos forestales de sus fincas. Las familias más jóvenes con hijos menores de 13 años ( 0,69 ha de promedio anual) o las que tienen adolescentes $(0,38 \mathrm{ha})$ evidencian tasas de desbosque anual relativamente más bajas en comparación con las que tienen hijos mayores o adolescentes $(1,09$ ha de promedio anual) o a las que tienen hijos exclusivamente mayores (1,92 ha). La diferencia es bastante notoria (cuadro 1).

Las familias más adultas, que pueden abarcar a dos o más generaciones, luego de varias décadas de residencia en el trópico tienen indiscutiblemente mayor capacidad económica para realizar labores de desbosque a un ritmo más alto que las familias más jóvenes. La disponibilidad de mano de obra familiar es un factor significativo en la capacidad de la familia para ampliar la extensión de las áreas cultivadas y las necesidades económicas son diferentes. Usualmente, si el agricultor mantiene la producción de su finca en el trópico, con al menos cuatro o más hectáreas de cacao o café, es porque ha logrado acumular cierto capital e incluso ha comprado más tierras. Dicho poder económico les permite retener a parte de sus hijos adolescentes o adultos en el núcleo y actividades de la empresa familiar y disponer de manera permanente de mano de obra. En este período de mayor consolidación productiva, la familia está dispuesta a asumir mayores riesgos económicos, dado que su base de sobrevivencia está más asegurada, y a centrarse en las labores agrícolas. Ellos no abandonan los cultivos de autoconsumo, pero su orientación económica es fundamentalmente la producción comercial.

Un factor adicional que explica la disparidad en las tasas de deforestación entre familias más jóvenes y más adultas es el tamaño de la finca o predio agrícola. Tal como demostramos en el gráfico 2, e igualmente explicamos en detalle en otro texto, los predios más grandes tienen tasas anuales de desbosque 6,13 veces que los predios más pequeños en tamaño (Bedoya, Gómez de la Torre y Anda, 2015)4.

No obstante, en realidad se trata de tasas de desbosque muy bajas en comparación, por ejemplo, a la cuantiosa deforestación anual causada por la agroindustria de biocombustibles para la apertura de plantaciones de palma africana en la región de Coca, en el nororiente de Ecuador. Por el contrario, la intensidad de la deforestación en Tena, depende de economías familiares con bajo o mediano nivel de capitalización y de las circunstancias actuales de la distribución de la tenencia de la tierra. 


\section{Gráfico 2. Tasa anual de deforestación}

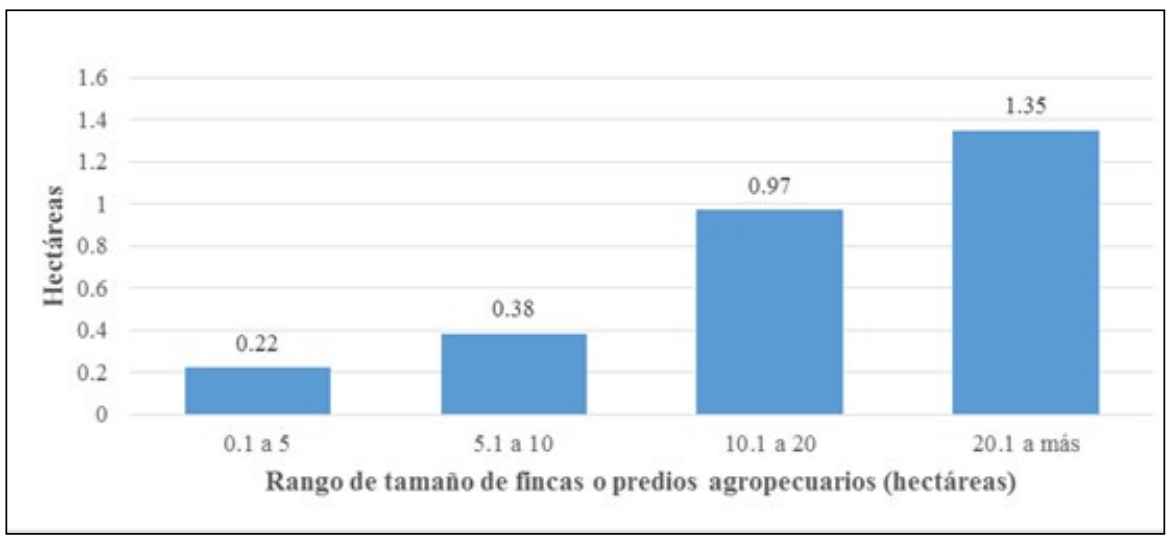

Fuente: Bedoya, Gómez de la Torre y Anda, 2015.

La cantidad de tierra que dispone cada familia depende a su vez del ciclo de vida de la familia. Alrededor de dos tercios de las familias recién formadas, con hijos pequeños, conducen unidades agrícolas menores de cinco hectáreas, en muchos casos adquiridas a través de herencias familiares o por la compra a colonos de más edad que han subdividido sus propiedades. Si en las décadas de 1960 y 1970 — es decir, a inicios de la colonización — los colonos accedían hasta un total de 50 hectáreas de tierras, en la actualidad el grueso de los agricultores, hijos de colonos, acceden a solo cinco hectáreas. Por el contrario, las familias mayores con hijos adultos, que se mantienen trabajando con sus padres, manejan propiedades de más de 30 hectáreas en un $80 \%$ de los casos. Es decir, los agricultores más jóvenes desarrollan tasas de desbosque más bajas no solo por la reducida extensión de sus cultivos sino también por el relativamente reducido tamaño de sus predios, y lo contrario sucede con las fincas más grandes. Tal como explica Barbieri (2005), actualmente los productores más jóvenes funcionan dentro de una frontera que se está cerrando, donde las tierras son cada vez más escasas, lo cual contrasta con décadas anteriores, cuando el libre acceso de tierras era mucho más amplio.

Existen otras dos razones que explican las diferencias de tasas de desbosque entre familias jóvenes y familias adultas más consolidadas. Si los hijos adolescentes o mayores que viven dentro o fuera de la finca, apoyan a los padres durante ciertos períodos del año, como parte de un esfuerzo o iniciativa de la empresa familiar, entonces la mano de obra en edad productiva de la familia seguirá 
siendo importante en la formulación de estrategias productivas e igualmente lo será sobre los niveles de la tasa anual de deforestación. Ello sucede en la medida que se requiera ampliar los terrenos cultivados para cubrir gastos de educación y mantenimiento de los hijos adolescentes en la ciudad, sobre todo en los períodos iniciales. Los mismos hijos que viven en la ciudad pueden ayudar a los padres durante los fines de semana, aunque ello es cada vez más complicado, tal como analizaremos en el siguiente acápite.

Sin embargo, los que tienen hijos exclusivamente en edad adulta son aquellos con tasas de deforestación más altas: 1,92 ha al año, lo cual significa 178\% más que las familias con hijos pequeños. En caso de las familias más adultas, se trata de aquellas que ya no tienen obligaciones económicas familiares, con padres o madres que oscilan entre 50 y 60 años de edad, que por el contrario reciben ayuda económica de sus hijos mayores o ellos mismos se han capitalizado como para contratar trabajadores para realizar las labores de desbosque.

En su conjunto, se observa en la evolución del ciclo de vida de las familias un tránsito de familias muy jóvenes, recién formadas, con predios pequeños, que trabajan la tierra sin mayores recursos de capital, con hijos muy pequeños, sin ayuda familiar, que practican una diversidad de actividades ocupacionales para su sobrevivencia, lo cual les permite disminuir y diversificar el riesgo y con una orientación al sembrío de cultivos anuales o en limpio para el autoconsumo, hacia su transformación en familias más maduras, capitalizadas, con fincas más extensas, con mano de obra disponible o con recursos para contratar trabajadores, con un predominio de cultivos permanentes, $\mathrm{y}$ con una orientación decididamente comercial. Todo indica que quienes han tenido éxito en la aventura colonizadora han sido los que han logrado consolidar una agricultura dirigida al mercado. No obstante, tal como observamos, esa consolidación económica ocurre preferentemente dentro de un ciclo de vida familiar.

Es por lo indicado que la orientación económica de los productores en Tena es posiblemente uno de los rasgos más importantes que se ha podido comprobar como factor determinante en las tasas de desbosque de los indicados agricultores. Encontramos que aquellos cuya orientación es fundamentalmente la producción agrícola o ganadera comercial su tasa anual de deforestación es de 1,71, mientras que aquellos que dirigen su producción fundamentalmente (no exclusivamente) hacia el autoconsumo su tasa anual es de 0,26 hectáreas al año (cuadro 2): una diferencia de 6,57 veces, demasiado grande como para pasar desapercibida. Expresado de otra manera, los que se orientan al mercado tienen una tasa de desbosque $558 \%$ mayor que los que practican una agricultura de autoconsumo. 
Los productores agrícolas más comerciales tienen preferentemente distintas variedades de cacao, tales como el nacional fino de aroma, el trinitario y otras que son nuevas especies de injertos. En el segundo caso - es decir, los agricultores orientados al autoconsumo-, conducen predios con extensiones muy reducidas de tierra cultivada, principalmente cultivos anuales —o también denominados como de ciclo corto - conjuntamente con algunas filas de cultivos de plátano u otras frutas, e igualmente, realizan otras actividades productivas u ocupacionales como fuentes de ingreso monetario, fuera de la unidad familiar agrícola.

\section{Cuadro 2. Orientación económica y tasa anual de deforestación}

\begin{tabular}{ll}
\hline Orientación económica de los agricultores & Tasa anual de deforestación \\
\hline Preferentemente el mercado 62 casos $(78 \%)$ & 1,71 ha al año \\
Preferentemente el autoconsumo 18 casos $(22 \%)$ & 0,26 ha al año \\
& $\begin{array}{l}\text { Una tasa de desbosque } 558 \% \text { mayor } \\
\text { entre los que orientan las actividades } \\
\text { de su finca al mercado en relación } \\
\text { Diferencia porcentual }\end{array}$ \\
& \\
\hline
\end{tabular}

Fuente: Bedoya, Gómez de la Torre y Anda, 2015.

\section{DESARROLLO DE MERCADOS LABORALES, ESTRATEGIAS OCUPACIONALES Y DEFORESTACIÓN EN UN CONTEXTO DE TRANSICIÓN FORESTAL}

En ese sentido, todo indica que la deforestación tiene en la actualidad un acentuado componente económico relacionado con la disponibilidad de recursos monetarios para retener los hijos en edad productiva dentro de la unidad familiar o para contratar trabajadores. Resulta muy sintomático que aquellas familias de agricultores que contratan trabajadores para los trabajos de deforestación tienen tasas anuales de desbosque $(2,18)$ hasta cuatro veces más altas que aquellos que solo lo hacen con la familia - hombres, mujeres o vecinos- $(0,52)$. En otras palabras, una tasa $319 \%$ mayor respecto de los segundos (cuadro 3).

Un agricultor del centro parroquial Ahuano comenta de manera muy precisa al respecto. Según dicho productor, actualmente ya no se tumba mucho para la agricultura. Hace treinta o cuarenta años se tumbaba más. Más bien la gente ha optado por «remontar porque estudian, van a la ciudad, buscan empleo, muy pocos 
trabajan en la agricultura». «La gente mayor de cuarenta, cincuenta años siguen en la agricultura para ayudar a sus hijos, para darles de comer a los jóvenes, pero sus hijos ya no trabajan o trabajan muy poco en la agricultura». Asimismo, afirma que «la gente mayor no se ha preocupado por extender su producción sino que mantienen el mismo terreno para la producción agrícola». «La gente tumba muy poco, y cuando tumba aprovechan la madera para la venta. Los jóvenes ya no quieren trabajar y por ello hay poca mano de obra (escasez de mano de obra) para la agricultura: por ejemplo, aquí hay gente de dieciocho, veinte años que uno dice ayúdame para cargar un saco grande de café te voy a pagar, son jóvenes que pueden, pero ellos dicen no si yo soy estudiado qué voy a cargar. ¡Peor van a estar en el campo trabajando!». Esta línea de argumentación fue repetida por numerosos agricultores.

\section{Cuadro 3. Tasa anual de deforestación según se contrate o no mano de obra entre agricultores en Tena (2014)}

\begin{tabular}{ll}
\hline Actividades realizadas & Tasa anual de desbosque \\
\hline $\begin{array}{l}\text { Solo exclusivamente familiares o minga. } \\
\text { No contrata jornaleros }(60 \text { casos })(75 \%)\end{array}$ & 0,52 hectáreas al año \\
Contrata jornaleros (20 casos) $(25 \%)$ & 2,18 hectáreas al año \\
Diferencia porcentual & $\begin{array}{l}\text { Una tasa } 319 \% \text { mayor entre los que } \\
\text { contratan respecto de los que no lo hacen }\end{array}$ \\
\hline
\end{tabular}

Fuente: Bedoya, Gómez de la Torre y Anda, 2015.

En ese sentido, no es que se haya resquebrajado la autoridad familiar dentro de las unidades de agricultores sino que la modernidad misma, con sus nuevos paradigmas, valores y estilos de vida virtualizados, se encargó de atraer a los jóvenes hacia la vida más urbana. De igual manera, los beneficios económicos del boom económico de la primera década de este siglo atrajeron a muchos agricultores jóvenes generando una migración de retorno hacia las ciudades andinas o costeñas, donde sus padres o abuelos nacieron, o en su defecto hacia los mismos núcleos urbanos medianos de la Amazonía, donde con menos trabajo obtienen más ingresos monetarios. Asimismo, en otros casos, los jóvenes consideraron que el esfuerzo o desgaste físico que demanda el trabajo agrícola no está suficientemente compensado por los correspondientes ingresos agrícolas, incluso en aquellos que pudiesen ser más altos que lo normal. La ley del menor 
esfuerzo (Boserup, 1965) privilegió las decisiones productivas de muchos de los trabajadores jóvenes de Tena.

En efecto, en la actualidad existe una notoria escasez de mano de obra joven en los núcleos familiares más adultos que fueron entrevistados. Un $45 \%$ de los agricultores afirmó tener problemas de ese tipo. Dicho fenómeno se origina por el proceso que acabamos de explicar. En términos económicos puede definirse tal escasez en términos relativos; es decir, en función del monto de dinero que cada familia está dispuesta a remunerar a sus hijos jóvenes para que se queden trabajando en la finca familiar, por un lado, o en función del salario que estén dispuestos a pagar a un trabajador contratado para la ejecución de diversas labores, por otro. No obstante, los que no tienen ese tipo de dificultades no significa que anteriormente no hayan enfrentado dicho fenómeno. Algunos lo han resuelto a través de la minga con los vecinos o la eventual ayuda de familiares. En cualquier caso, los que enfrentan problemas de escasez de fuerza de trabajo tienen una tasa anual de desbosque de 0,58 frente a los que no enfrentan tal dificultad, cuya tasa es de 1,26 . Ello equivale a un $117 \%$ de incremento respecto de los que sí tienen el problema (cuadro 4).

\section{Cuadro 4. Tasa anual de deforestación según escasez de mano de obra entre agricultores en Tena (2014)}

\begin{tabular}{ll}
\hline Actividades realizadas & Tasa anual de desbosque \\
\hline Sí tienen escasez (36 casos: $45 \%$ de los casos) & 0,58 hectáreas al año \\
No tienen escasez (44 casos: $55 \%$ de los casos) & 1,26 hectáreas al año \\
Diferencia porcentual & Una tasa $117 \%$ mayor entre los que \\
& $\begin{array}{l}\text { no tienen problemas de escasez de } \\
\text { mano de obra. }\end{array}$ \\
\hline
\end{tabular}

Fuente: Bedoya, Gómez de la Torre y Anda 2015.

En las fases iniciales de colonización de la Amazonía ecuatoriana o peruana o brasileña, cuando la tierra disponible era muy abundante y la mano de obra escaseaba, la opción de abrir otra parcela dentro de la misma finca o trasladarse a otra zona y deforestar para mantener la producción agrícola y los ingresos monetarios era la alternativa más racional. Durante dos o tres semanas, un padre y un hijo joven podían cortar el monte y así reiniciar el ciclo de producción, cada vez que los rendimientos decrecientes de los agricultores aparecían y el control 
de malezas era imposible. La alternativa de la intensificación del uso del suelo, a través del uso de insumos modernos no era una alternativa viable pues era costosa o no rendía beneficios inmediatos. Las tasas de desbosque resultado de una agricultura comercial muy incipiente basada en el rozo y quema, e igualmente, la escasez de trabajadores, eran dos caras de una misma moneda (Bedoya y Klein, 1996). En la actualidad tal fenómeno se ha extendido a las fases posteriores del ciclo de vida familiar y ha adquirido una influencia distinta. Es justamente la escasez de mano de obra joven uno de los factores que frena la deforestación.

En resumen, encontramos dos tipos de escasez de mano de obra en la región del Tena. Una primera vinculada con las fases iniciales del ciclo de vida familiar. Ello conduce a un tipo de deforestación dirigida a introducir cultivos de autoconsumo, pero debido a que tales productos se siembran en extensión pequeña el desbosque no es muy intenso. Una segunda forma de escasez es la vinculada con fases posteriores del ciclo familiar, y donde el déficit de fuerza de trabajo se debe a que los hijos adultos jóvenes optan por abandonar la unidad agrícola para residir y trabajar en las ciudades. En ambos casos, la falta de trabajadores frena la deforestación. Por el contrario, las familias más antiguas que no tienen déficit de fuerza de trabajo dado que logran retener a sus trabajadores generan las tasas de desbosque más altas (ver también Bilsborrow, 1997, p. 36). La mayor disponibilidad de mano de obra induce a mayores tasas de desbosque, en especial cuando la orientación de la empresa familiar es decididamente el mercado.

Una tendencia diferente sucede con los padres o jefes de familia. Los datos demuestran de manera contundente que, cuando uno de los dos jefes de familia trabaja fuera de la unidad agropecuaria como albañil, chofer, funcionario público, turismo, cuidado de niños y otros, las tasas de desbosque suelen ser más bajas ( 0,48 ha anuales) en contraste a aquellas familias que se concentran en la agricultura o ganadería (1.45 ha). Es decir, 202\% mayor en los segundos respecto de los primeros, lo cual es una diferencia significativa (cuadro 5). La mayor dependencia en estas actividades agropecuarias genera una mayor presión sobre el bosque y, viceversa, la menor dependencia una menor presión. Esto último, es decir la diversificación laboral fuera de la unidad agropecuaria, constituye uno de los rasgos típicos de la transición forestal (Angelsen y Rudel, 2003, p. 97).

Por tanto, si el padre o madre de la unidad familiar agrícola dependen de estas actividades para su sobrevivencia o disponen de recursos monetarios como para contratar trabajadores, debido a que se han capitalizado con el trascurso de los años de su residencia en el trópico o tienen cada vez menos obligaciones económicas familiares, entonces sus tasas de deforestación serán relativamente más altas. 
Cuadro 5. Tasa anual de deforestación según se realicen actividades adicionales a la agricultura y ganadería entre agricultores en Tena (2014)

\begin{tabular}{ll}
\hline Actividades realizadas & Tasa anual de desbosque \\
\hline $\begin{array}{l}\text { Exclusivamente agricultura y ganadería } \\
\text { (34 casos) }\end{array}$ & 1,45 hectáreas al año \\
$\begin{array}{l}\text { Adicionalmente fuera de la finca: tienda, } \\
\text { chofer, albañil, contrata en agricultura o } \\
\text { ganadería, funcionario público, turismo, } \\
\text { cuidado de niños y otros (46 casos) }\end{array}$ & 0,48 hectáreas al año \\
$\begin{array}{l}\text { Diferencia porcentual } \\
\text { Una tasa 202\% mayor entre los que } \\
\text { realizan actividades fuera de la finca } \\
\text { respecto de los que trabajan exclusiva- } \\
\text { mente en agricultura y ganadería }\end{array}$ \\
\hline
\end{tabular}

Fuente: Bedoya, Gómez de la Torre y Anda, 2015.

Ahora bien, una dependencia en la agricultura o ganadería que no implique un uso sostenible del bosque en actividades relacionadas con la caza y la pesca también genera presión sobre este. Los agricultores colonos, o aquellos hijos de colonos que nunca aprendieron a cazar o pescar pero que todavía dependen de la agricultura o ganadería para su sobrevivencia, tienen una tasa promedio de deforestación de 1,51 hectáreas anuales, mientras la de los que sí cazan o pescan es de 0,63 (cuadro 6), lo cual equivale a una diferencia de $140 \%$. Los primeros dependen de la venta de sus productos agropecuarios para obtener proteínas y, por lo mismo, requieren transformar el bosque en espacios agrícolas o ganaderos. Por el contrario, los colonos que cazan o pescan para fines de autoconsumo ejercen una menor presión destructiva. Los datos así lo confirman.

Cuadro 6. Tasa anual de deforestación según se realicen actividades de caza, pesca y recolección entre agricultores en Tena (2014)

\begin{tabular}{ll}
\hline Realizan actividades de caza o pesca & Tasa anual de deforestación \\
\hline Si cazan o pescan o recolección (42 casos) & $\begin{array}{l}0,63 \text { hectáreas al año } \\
\text { No cazan o pescan o recolectan (38 casos) }\end{array}$ \\
$\begin{array}{l}1,51 \text { hectáreas al año } \\
\text { Diferencia porcentual }\end{array}$ & $\begin{array}{l}\text { Una tasa } 140 \% \text { mayor entre los que no } \\
\text { cazan yescan respecto de los que sí } \\
\text { lo hacen }\end{array}$ \\
\hline
\end{tabular}

Fuente: Bedoya, Gómez de la Torre y Anda, 2015. 
Se ha demostrado en otros estudios (Bedoya, 1995) que en sociedades tradicionales donde la agricultura es solo parte de una estrategia de sobrevivencia conjuntamente con la caza, la pesca y la recolección, las tasas de deforestación suelen ser relativamente muy bajas. Dicha estrategia es propia de grupos nativos amazónicos más tradicionales. Lo peculiar del caso, sin embargo, es que, durante el trabajo de campo de investigación realizado en Tena, algunos colonos han afirmado cazar, pescar y recolectar, sobre todo aquellos que han tenido vínculos cercanos con grupos indígenas del lugar, de quienes aprendieron tales prácticas y así lograron una adaptación más rápida al ecosistema tropical.

En síntesis, podemos concluir que tanto una mayor diversificación ocupacional en actividades tradicionales de caza, pesca y recolección como también una mayor participación en el mercado laboral fuera de la unidad familiar o en actividades económicas independientes, generadoras de recursos monetarios, conduce a una menor necesidad de transformar las zonas boscosas en espacios agrícolas o ganaderos; en otras palabras, provoca una menor presión sobre el bosque. Por lo mismo, en ambos casos las tasas de deforestación anual son menores en comparación con los agricultores que no realizan actividades tradicionales de caza, pesca o recolección o cuando no tienen otras ocupaciones o ingresos fuera de la unidad agropecuaria.

\section{PERCEPCIONES SOBRE EL BOSQUE, EL REALCE (PURMAS) Y SU IMPACTO EN LA DEFORESTACIÓN}

La dinámica de la deforestación en Tena está igualmente condicionada por las percepciones que se tiene sobre el uso o no uso que se debe hacer del bosque. En los talleres, las encuestas, y sobre todo en las entrevistas realizadas en la región del Tena, las opiniones y comentarios que se tienen sobre el bosque resultaron sumamente valiosas. Una mayoría relativa de 55\% argumentó que el bosque debía transformarse en espacio de uso agrícola y una minoría de $45 \%$ que el bosque debía mantenerse como tal. Quienes creen que el bosque debe servir para usos directamente comerciales, además de la agricultura y ganadería tienen una tasa de deforestación promedio es de 1,23 hectáreas al año, y quienes consideran que no debe tocarse, una tasa anual de 0,35 hectáreas (cuadro 7). Ello equivale a un $251 \%$ mayor en los primeros respecto de los segundos. Otra diferencia importante: 
Cuadro 7. Tasa anual de deforestación según percepción de uso del bosque según agricultores en Tena (2014)

\begin{tabular}{ll}
\hline Percepción sobre uso del bosque & Tasa anual de deforestación \\
\hline $\begin{array}{l}\text { Debe mantenerse el bosque virgen (36 casos) } \\
(45 \%)\end{array}$ & 0,35 hectáreas al año \\
$\begin{array}{l}\text { Debe transformarse en espacio agrícola y/o } \\
\text { ganadero (44 casos) }(55 \%)\end{array}$ & 1,23 hectáreas al año \\
$\begin{array}{l}\text { Diferencia porcentual } \\
\text { Una tasa } 251 \% \text { mayor entre los que } \\
\text { buscan transformar el bosque respecto } \\
\text { de los que son conservacionistas }\end{array}$ \\
\hline
\end{tabular}

Fuente: Bedoya, Gómez de la Torre y Anda, 2015.

Lógicamente, quienes creen que no se debe deforestar no es porque necesariamente hayan elaborado un discurso o una narrativa libre de condicionamientos materiales. Ello se observa muy claramente entre los agricultores de mayor edad, con familias constituidas e incluso multigeneracionales. Su forma de pensar se debe a cálculos económicos inmediatos y a expectativas sobre el futuro de sus hijos y nietos. Tal es el caso de un colono de la localidad de San Pedro de Arajuno. Dicho agricultor migró hace cuatro décadas desde la provincia de Bolívar. El mencionado colono agricultor percibe que «progreso» significa mantener el bosque para que cuando falte terreno: «hablemos de mis hijos, de mis nietos, cuando necesiten ellos para hacer yuca, plátanos, ahí podría botar». Ese decir, el bosque está reservado para que «lo ocupen» las futuras generaciones de la familia. No existe ninguna ruptura con la actitud crematística que los colonos tuvieron al llegar a la Amazonía ecuatoriana hace varias décadas. Se trata de la misma percepción de explotación y transformación de la frontera tropical, pero en este caso es simplemente postergada para beneficio de generaciones futuras. $\mathrm{Si}$ a corto plazo deciden transformarlo para actividades agrícolas comerciales, este no resultaría rentable tanto por la calidad de la tierra como por la cantidad de esfuerzo que requiere cultivar productos como el café y el cacao. «Si se bota, se hace el trabajo y al año ya se cosecha, para meter el cacao y el café entonces tocaría mantener y eso es complicado [...]. Tal vez en el futuro se tumbe el monte grande para agricultura algún rato, como para hacer unas cosechas de plátano, yuca, maíz. Pero para café o cacao ya no sirve porque el terreno es muy árido, no produce». De igual manera, remarcó que tumbar el monte para cultivos permanentes no sirve porque estos requieren de mucha mano de obra, al contrario 
de lo que sucede con los cultivos anuales, que demandan menos fuerza de trabajo. Un problema presente de disponibilidad de fuerza de trabajo posterga la decisión de la explotación del bosque.

En cualquier caso, los agricultores perciben en la actualidad que la tierra es más escasa que antes, dado el nuevo contexto de una frontera cada vez más cerrada y de subdivisión de tierras, a través de la herencia o la venta a nuevos agricultores. La referida percepción de escasez induce indiscutiblemente a pensar que los espacios en descanso o en realce deben tarde o temprano regresar a la producción agrícola o ganadera. Para Pálsson (2001, p. 84) tal visión sobre el bosque se sustenta en paradigmas «orientalistas» y representa una relación de reciprocidad negativa y unilineal entre seres humanos y naturaleza.

Por otro lado, no obstante, el indicado agricultor también expresó opiniones sobre la necesidad de mantener el bosque primario «grande», basadas en argumentos relacionados con los servicios ambientales que este proporciona. Para dicho colono, el bosque también funciona como una reserva de agua, dado que cuando se deforesta en exceso, la tierra se seca muy fácilmente y necesita humedad: «Por ejemplo, aquí ocho días que haya sol, el terreno se parte, se seca. La montaña mantiene fresco, hasta hay esteros, nacen riachuelos de las colinas. Entonces la montaña no seca mucho al agua. Pero si usted bota todo eso se seca. Aquicito tengo una vertiente, entonces eso, si hay quince días que haya verano, entonces se seca, toca mantener la sombra [...]. El monte sirve para mantenimiento de la tierra para que absorba la humedad, porque al despejar todo se hace árido, se seca y ya no sirve para nada». En pocas palabras, al mencionado colono le interesa mantener el bosque para mantener la humedad, de lo contrario el lugar donde vive y trabaja estaría «muy seco». En este último caso, las percepciones sobre el bosque se construyen en una actitud proteccionista basada en una relación de reciprocidad equilibrada. Se requiere proteger a la naturaleza por los servicios ambientales que ella proporciona. En síntesis, todo indica que el mencionado colono oscila entre una visión economicista y crematística del bosque, donde la reciprocidad entre individuo y naturaleza es negativa, y una percepción cercana a una actitud paternalista que no excluye el dominio sobre la naturaleza pero que implica una cierta protección, cuidado y mutua reciprocidad (ver Pálsson, 2001, pp. 84-91).

Otro espacio susceptible de análisis es el denominado realce o tierras en descanso, en la medida que dichos espacios pueden constituir futuros bosques secundarios si es que son dejados en descanso durante un número suficiente de años. No obstante, las percepciones de los agricultores respecto del realce se 
orientan en otra dirección. Para numerosos agricultores los terrenos en descanso dependen directamente de su extensión y ubicación en relación con la carretera. Los agricultores colonos que fueron entrevistados suelen conducir hasta dos fincas, separadas una de otra por varios kilómetros de distancia: una primera cerca de la carretera o camino troncal y otra lejos de ella. Las más cercanas a la carretera tienden a ser más pequeñas en tamaño y el uso del suelo es bastante intensivo, en comparación con las más lejanas, que con mayor frecuencia son más grandes y tienen un uso del suelo más extensivo. Tal es el caso de una agricultora de la comunidad San Pedro de Arajuno, propietaria de dos terrenos: uno de dos hectáreas cercano a la carretera y otro de seis hectáreas lejos de ella. Mientras más grande el terreno, mayor cantidad de tierras en descanso. El terreno con una extensión de 2 ha no tiene ninguna parcela en descanso. «Como es poco terreno, no hay como dejar que se desperdicie el terreno, toca aprovechar sembrando». En cambio el terreno más grande, con una extensión de 6 ha, a pesar de ser visto por ellos como un terreno pequeño, tiene una parcela en descanso. Generalmente la tierra se la deja descansar por dos o tres años para que se «haga realce», después de ese tiempo «se hace monte» (crecen árboles más grandes y fuertes). Cuando se hace monte «toca rozar por dentro, dejar los árboles y luego bajar los arboles después». Ello también significa que las familias colonas prefieren mantener «una reserva de realce» de un tiempo máximo de tres años, porque después de este tiempo crecen los árboles, lo cual genera una mayor demanda de fuerza de trabajo.

Igualmente, las reflexiones de otra agricultora de la misma comunidad de Bolívar al respecto son también bastante útiles. La agricultora mencionada, más joven que la colona anterior, afirma que en la reserva que tiene con su familia ha crecido un realce (cuando ya ha crecido monte) que generalmente contiene árboles no maderables, como la chilca, hierbas y monte en general, que carecen de valor comercial. Para la agricultora, los indicados terrenos representan únicamente una «esperanza» para cultivos a futuro. No son tierras que descansan por motivos de conservación de la biodiversidad, sino una reserva que permitirá renovar nutrientes de los suelos para una producción posterior: «Es bueno cuando se deja descansar, se siembra maíz. Da buena producción. No se necesita abonar, solo se siembra nomás y se mantiene limpio y produce bien». Por lo mismo, la percepción de los productores sobre el realce tiene una connotación preferentemente economicista. En todo caso, dicha percepción colona sobre el realce ayuda a comprender la razón de que muchos colonos no prefieren una tierra que se mantenga indefinidamente en bosque virgen o secundario sin ninguna producción, lo que se debe a que no representa trabajo o riqueza productiva. Ello se diferencia con las poblaciones 
nativas amazónicas en las cuales las tierras en descanso sí son productivas, pues de ellas se siguen extrayendo productos de manera indefinida o durante muchos años (Irvine, 1989; Bedoya, 1995).

La referida connotación economicista entre los colonos sobre los espacios en realce también se puede percibir a escala colectiva. En los talleres participativos realizados con miembros de la comunidad de San Pedro de Arajuno se pudo comprobar dicha ambivalencia. Aunque no siempre se solicitó a los productores agrícolas de todas las mesas o grupos de trabajo su percepción sobre el uso que se debe tener del bosque, casi siempre salieron a relucir comentarios u opiniones al respecto. En una primera mesa, conformada exclusivamente por mujeres jóvenes y adultas, donde se les pidió dibujar el mapa de la comunidad, ellas de manera espontánea escribieron comentarios, utilizaron términos o dibujaron imágenes que evidenciaban sus puntos de vista sobre lo que significa el bosque primario. Junto al bosque dibujaron árboles relativamente grandes y muchas aves, escribieron conceptos tales como «plantas medicinales en caso de emergencia» y redactaron las palabras «bosque protegido». En el mapa, el bosque ocupa un $30 \%$ del plano. En la parte del mapa donde se encuentra el cultivo del cacao, naranjilla y otros, las mujeres escribieron «bosque destruido para siembra y viviendas». Es decir, la transformación del bosque primario en espacio agrícola o ganadero tiene una connotación negativa. Significa destrucción, en contraposición a un bosque primario que constituye una reserva de plantas medicinales y hábitat de aves. La percepción de reciprocidad equilibrada, tal como lo define Pálsson (2001, pp. 84-91), en la relación entre mujeres y bosques resultaba evidente.

Seguidamente, en otro grupo de trabajo, conformado exclusivamente por hombres jóvenes y adultos, donde igualmente se les pidió dibujar el mapa de la comunidad, también se evidenciaron percepciones muy específicas sobre el uso del bosque. Ante todo, los hombres redujeron a su mínima expresión el espacio dedicado a graficar el bosque virgen, a casi un 5\% del mapa, mientras que la distribución de las calles empedradas, las viviendas, la escuela, la cancha de fútbol etc., ocupan dentro del mapa un espacio bastante mayor, prácticamente el resto del espacio dibujado. Lo interesante del caso es que una vez más y de forma también espontánea colocaron comentarios sobre el bosque. Escribieron las palabras «caza», «talan», «madera», «negocio», «vivienda», «reserva agrícola o ampliar frontera». La diferencia de las percepciones entre hombres y mujeres resultaba bastante notoria. Los hombres perciben al bosque como un espacio a ser transformado para la sobrevivencia de la familia y para la generación de ingresos monetarios. Se trata de una visión sobre el bosque claramente mercantilizada y crematística. 
Si contrastamos ambas mesas de discusión, la conclusión sería que entre las mujeres el bosque aparece como un espacio de valores de uso y entre los hombres como un lugar cuya transformación permite obtener valores de cambio. No obstante, la opinión recogida en una tercera mesa conformada solo por hombres jóvenes y adultos mayores demuestra que las diferencias de género no constituyen un indicador confiable como para argumentar que las diferentes percepciones sobre el bosque tienen una connotación conservacionista solo en las mujeres y depredadora entre los hombres. En dicha tercera mesa, aunque el bosque abarca solo un $20 \%$ a $25 \%$ del mapa, se escribieron comentarios tales como que «el bosque sirve para obtener sombra y lluvia, también para reserva de plantas medicinales»; "se ha talado el bosque para (uso) agropecuario». Igualmente, se diferencia entre bosque primario y bosque secundario. De manera paralela se dibuja el espacio dedicado a la agricultura, donde se señalan los cultivos que siembran los agricultores de San Pedro de Arajuno, tales como café, cacao, maíz y yuca. En pocas palabras, un sector de los hombres también manifiesta una percepción basada en una relación de mutua o equilibrada reciprocidad. Dicha visión no se limita a las mujeres.

Todo indica que las decisiones finales sobre el uso del bosque dependen más de una serie de cálculos económicos de mediano y largo plazo que realizan los productores. Un elocuente ejemplo de ello nos lo proporcionó un agricultor que argumentó que en su momento aceptaría un «contrato» con Socio Bosque para «ceder» unas 30 hectáreas de su bosque y recibir 900 dólares al año, manteniendo para su propio uso y beneficio otras 10 hectáreas. En este último caso su propuesta era deforestar esta parte de la finca para fines agrícolas o ganaderos, según las condiciones del mercado. Independientemente de que tal arreglo pueda ser factible, el hecho es que no es tanto el criterio conservacionista el que condiciona tal tipo de decisión, sino los cálculos económicos que el propio agricultor establece.

\section{COMENTARIOS FINALES}

Una virtud del trabajo de campo etnográfico combinado con encuestas es la posibilidad de descubrir la racionalidad de los productores individuales dentro de un contexto de economía regional y global. La presente investigación demuestra, en primer lugar, cómo las tendencias que suceden a nivel macro en la región de Tena y en toda la Amazonía, en especial respecto del cierre de la frontera y la transición forestal, se reflejan en la racionalidad productiva y en la vida cotidiana de los colonos agricultores. De acuerdo con la información cualitativa 
de campo, los agricultores parecen sentirse atrapados en una dinámica aparentemente contradictoria. Por un lado, se sienten atraídos por el menor esfuerzo de trabajo (Boserup, 1965), los estilos de vida urbanos o semiurbanos y los ingresos monetarios urbanos que los conducen a abandonar del campo y a reducir la deforestación, y por otro lado, son también conscientes de que las tierras de frontera son cada vez más escasas, que requieren ser reservadas pero no para su conservación (salvo algunos grupos de mujeres) sino para fines crematísticos futuros. No obstante, tales estrategias productivas de ninguna manera son simples respuestas automáticas a procesos macrorregionales o globales. Los ciclos de vida de las familias productoras, la disponibilidad de mano de obra familiar, la diversificación productiva y ocupacional, los mecanismos endógenas de articulación con el mercado, y finalmente, la diversidad de percepciones que los productores construyen sobre los bosques y los denominados espacios en descanso, realce o monte alto o bosques secundarios, conforman factores que prueban no solo la multicausalidad de los procesos socioambientales, sino que también grafican la importancia de los mismos agentes directos de la deforestación en la toma de decisiones sobre el manejo de los recursos naturales. Tales decisiones tienen un acentuado componente productivo y demográfico, como también una clara connotación cultural.

\section{REFERENCIAS BIBLIOGRÁFICAS}

Angelsen, Arild y Thomas K. Rudel (2013). Designing and Implementing Effective REDD+Policies: A Forest Transition Approach. Review of Environmental Economics and Policy, 7(1), Winter 2013, 91-113 https://doi.org/10.1093/reep/res022

Aramburú, Carlos y Eduardo Bedoya (1987). Poblamiento y uso de los recursos en la Amazonía Alta; el caso del Alto Huallaga. En Carlos Mora y Carlos Aramburú (eds.), Desarrollo amazónico: una perspectiva latinoamericana. Lima: Centro de Investigación y Promoción Amazónica (CIPA) e Instituto Andino de Estudios en Población y Desarrollo (INANDEP).

Barbieri, A. F., R. E. Bilsborrow y W. K. Pan (2005). Farm household lifecycles and land use in the Ecuadorian Amazon. Population and Environment, 27(1), 1-27. https://doi.org/10.1007/s11111-005-0013-y

Bedoya, Eduardo (1995). The Social and Economic Causes of Deforestation in the Peruvian Amazon basin: natives and colonists. En The Social Causes of Environmental Destruction in Latin America. Linking Levels of Analysis. Ann Arbor: University of Michigan Press. 
Bedoya Garland, Eduardo y Lorien Klein (1996). Forty years of Political ecology in the Upper Peruvian Forest: The Case of Upper Huallaga. En Leslie E. Sponsel, Thomas Headland y Robert G. Bailey (eds.), Tropical Deforestation. The Human Dimension I (pp. 165-186). Nueva York: Columbia University Press.

Bedoya Garland, Eduardo, Sara Gómez de la Torre y Susana Anda (2015). «La ecología política de la deforestación en la Amazonía de Ecuador». Informe final para SENESCYT. Programa Prometeo. Quito Ecuador.

Bilsborrow, Richard (1994). Population, development and deforestation: Some recent evidence. En United Nations, Department of Economic and Social Information and Policy Analysis (ed.), Population, Environment, and Development (pp. 117-134). Nueva York: United Nations Press.

Bilsborrow, Richard (1997). Population dynamics and deforestation in Latin America: Research findings and policy issues. Nidi Hostee Lecture Series, 4, La Haya.

Bilsborrow, R., A. Barbieri y W. Pan (2004). Changes in population and land use over time in the Ecuadorian Amazon. Acta Amazónica, 34, 635-647. https://doi. org/10.1590/S0044-59672004000400015

Boserup, Ester (1965). The Conditions of Agricultural Growth. The Economies of Agrarian Change under Population Pressure. Nueva York: Aldine.

Bryant, R. (1998). Power, Knowledge and Political Ecology in the Third World. Progress in Physical Geography, 22(1), 79-94.https://doi.org/10.1191/030913398674890974

Bryant, R. L. y S. Bailey (1997). Third world political ecology. Londres: Routledge

Deadman Peter, Derek Robinson, Emilio Moran y Eduardo Brondizio (2004). Colonist household decision making and land-use change, in the Amazon Rainforest: and agent-based simulation. Environment and Planning. B: Planning and Design, (31), 693-709.

Godoy, Ricardo, Kathleen O’Neill, Stephen Groff, Peter Kostishack, Adoni Cubas, Josephien Demmer, Kendra Mcsweeney y Johannes Overman (1997). Household determinants of deforestation by amerindians in Honduras. World Development, 25(6), 977-987. https://doi.org/10.1016/S0305-750X(97)00007-7

Gómez de la Torre, Sara, Susana Anda y Eduardo Bedoya Garland (2017). Procesos políticos y estructurales de la deforestación en la Amazonía: el caso de Tena, Ecuador (2014). Espacio y Desarrollo, (29), 7-36.

Grijalva, J., Venus Arévalo, Charles Wood (2004). Expansión y trayectoria de la ganadería en la Amazonía. Publicación Miscelánea, 125. Quito: INIAP, Editorial Tecnigrava.

INEC-Ecuador (Instituto Nacional de Estadísticas y Censos) (2010). VII Censo de Población y VI de Vivienda. Quito. 
INEC-Ecuador (Instituto Nacional de Estadísticas y Censos) (2001). VI Censo de Población y V de Vivienda. Quito.

Irvine, D. (1989) Succession Management and Resource Distribution in an Amazonia Rainforest. Advances in Economic Botany, 7, 223-237.

Lu, Flora, Clark Gray, Richard E. Bilsborrow, Carlos Mena, Christine M. Erlien, Jason Bremner, Alison Barbieri y Stephen J. Walsh (2010) Contrasting Colonist and Indigenous Impacts on Amazonian Forests. Conservation Biology. Research Note, 24(3), 881-885. https://doi.org/10.1111/j.1523-1739.2010.01463.x

Macdonald, Theodore (1997). De cazadores a ganaderos. Quito: Abya Yala.

ORDEPLAN-Ecuador (2012). Plan de Desarrollo y Ordenamiento Territorial Parroquia Ahuano. Ahuano, Tena. http://app.sni.gob.ec/visorseguimiento/DescargaGAD/ data/sigadplusdiagnostico/1560602670001_MODELO\%20DE\%20GESTION\%20AHUANO_15-05-2015_17-29-45.pdf

Mather, Alexander. (1992). The forest transition. Area, (24), 367-379.

Pálsson, Gísli (2001). Relaciones humano-ambientales. Orientalismo, paternalismo y comunalismo. En Philippe Descola y Gísli Pálsson (eds.), Naturaleza y sociedad. Perspectivas antropológicas (pp. 80-100) México D. F.: Siglo XXI.

Perz, Stephen (2001). Household demographic factors as life cycle determinants of land use in the Amazon. Population Research and Policy Review, (20), 159-186.

Perz G. Stephen y David Skole (2003). Secondary Forest Expansion in the Brazilian Amazon and the Refinement of Forest Transition Theory. Society and Natural Resources, (16), 277-294. https://doi.org/10.1080/0894192039017885667

Perz, Stephen y Robert Walker (2002). Household Life Cycles and Secondary Forest Cover Among Small Farm Colonists in the Amazon. World Development, 30(6), 1009-1027. https://doi.org/10.1016/S0305-750X(02)00024-4

Pfaff, A. y R. Walker (2010). Regional interdependence and forest «transitions»: Substitute deforestation limits the relevance of local reversals. Land Use Policy, 27(2), 119-129. https://doi.org/10.1016/j.landusepol.2009.07.010

Pichón, Francisco (1996). Settler Agriculture and the Dynamics of Resource Allocation in Frontier Environments. Human Ecology, 24(3), 341-371. https://doi.org/ 10.1007/BF02169394

Pichón, Francisco (1997). Colonist land-allocation decisions, land use, and deforestation in the Ecuadorian Amazon frontier. Economic Development and Cultural Change, 45, 707-744. https://doi.org/10.1086/452305

Pichón, Francisco y Richard Bilsborrow (1999). Land Use Systems, Deforestation and Demographic Factors: Farm-Level evidence from Ecuador. En Richard Bilsborrow y Daniel Hogan (eds.), Population and Deforestation in the Humid Tropics 
(pp. 175-206). Lieja: International Union for the Scientific Study of Population (USSP).

Rudel Thomas et al. (2002). A Tropical Forest Transition. Agriculture Change, Out Migration, and Secondary Forests in the Ecuadorian Amazon. Annals of the Association of the American Geographers, 92(1), 87-102. https://doi. org/10.1111/1467-8306.00281

Sierra, Rodrigo (2013). Patrones y factores de deforestación en el Ecuador Continental, 1990-2010. Quito: Conservación Internacional Ecuador. Forest Trend.

Trujillo, Jorge (1986). Los pueblos indígenas y la colonización en la Amazonía ecuatoriana. En Desarrollo amazónico: una perspectiva latinoamericana (pp. 427-452). Lima: CIPA-INANDEP.

Uquillas, Jorge (1984). Colonization and spontaneous settlement in the Ecuadorian Amazon. En Marianne Schmink y Charles Wood (eds.), Frontier expansion in Amazonia (pp. 261-284). Gainesville: University of Florida.

Uquillas, Jorge (1987). Colonización y asentamientos espontáneos en la Amazonía ecuatoriana. En Desarrollo amazónico: una perspectiva latinoamericana (pp. 359-383). Lima: CIPA-INANDEP.

Walker Robert y Alfredo Kingo Oyama Homma (1996). Land use and land cover dynamics in the Brazilian Amazon: an overview. Ecological Economics, (18), 67-80. https://doi.org/10.1016/0921-8009(96)00033-X 